\title{
POSSIBILIDADES PARA O ENSINO DE HISTÓRIA EM DIVERSAS FONTES HISTÓRICAS A PARTIR DO CASO SACCO E VANZETTI
}

\author{
POSSIBILITIES FOR THE TEACHING OF HISTORY IN \\ VARIOUS HISTORICAL SOURCES FROM THE CASE SACCO \\ AND VANZETTI
}

\begin{abstract}
Eduardo da Silva Soares
Professor de História e Geografia da rede municipal de Cachoeira do Sul Doutorando em História pela Universidade Federal de Santa Maria, Brasil Mestre em História pela Universidade Federal de Santa Maria, Brasil e-mail: eduardosoares@rocketmail.com
\end{abstract}

DOI:

http://dx.doi.org/10.26512/hh.v6i11.11013

Recebido em 16 de maio de 2017

Aprovado em 29 de março de 2018

\section{RESUMO}

Este artigo discute as possibilidades de ensino através das fontes e dos recursos disponibilidades na internet para estudar o caso Sacco e Vanzetti. O referido caso ocorreu entre os anos 1920, nos Estados Unidos da América. Ao longo deste artigo surgem propostas de estudos com conceitos que podem ser relacionados ao caso supracitado, por exemplo: e/imigração, fascismo, Red Scare, entre outros. Há, também, o levantamento e a especulação sobre os recursos, as ferramentas, as fontes e as alternativas que os estudos de caso possibilitam aos professores. Os objetivos foram básicos, ou seja, focaram em breves reflexões referentes aos conceitos sendo explorados na sala de aula. Em suma, são destacados os momentos da formação de considerações teóricas plausíveis de serem realizados pelos professores com os alunos.

Palavras-Chave: Ensino de História; Estudo de Caso; Caso Sacco e Vanzetti; Fontes e recursos na educação

\begin{abstract}
This article discusses the possibilities of teaching through the sources and resources available on the internet to study the Sacco and Vanzetti case. This case occurred between the years 1920, in the United States of America. Throughout this article, proposals for studies with concepts that may be related to the aforementioned case arise, for example: e / immigration, fascism, Red Scare, among others. There is also a survey and speculation on the resources, tools, sources and alternatives that the case studies make possible for teachers. The objectives were basic, that is, they focused on brief reflections regarding the concepts being explored in the classroom. In sum, the moments of the formation of plausible theoretical considerations to be realized by the teachers with the students are highlighted.
\end{abstract}

Keywords: History Teaching; Case study; Sacco-Vanzetti case; Sources and resources in the education 


\section{INTRODUÇÃO}

O caso Sacco e Vanzetti, que "abalou o mundo" na década de 20, tornou-se um marco para o movimento operário e anarquista. Símbolos do movimento pelo fim da pena de morte, Nicola Sacco e Bartolomeo Vanzetti - os dois sujeitos que protagonizam o caso aqui estudado - eram italianos, imigrantes e trabalhadores nos Estados Unidos da América (EUA), características que foram determinantes para suas condenações à pena de morte.

Os dois trabalhadores foram considerados mártires por boa parte do movimento operário mundial, principalmente, pelos anarquistas, mas também por escritores e professores que manifestaram suas impressões e opiniões referentes ao caso ocorrido em 1927. É importante pontuar que o caso Sacco e Vanzetti ocorre em um contexto de pós Primeira Guerra Mundial (1914-1918) e pós Revolução Russa (1917), em um EUA marcado pela Red Scare ${ }^{1}$ (1919-1920).

É pertinente perceber que a Primeira Guerra Mundial envolveu as nações europeias e os EUA. No caso, este país não sofreu com a destruição de seu território. Porém, os governantes tiveram que enfrentar a oposição de muitas pessoas no país, fossem elas estadunidenses ou imigrantes. Nesse sentido, o anarquismo se destacou internacionalmente com discursos antimilitares. E, conforme Kenyon Zimmer $^{2}$, grande parte dos anarquistas presentes nos EUA foram contrários ao conflito.

Sem dizer que os anarquistas não eram considerados confiáveis, pois, além de possíveis terroristas, poderiam defender a nacionalidade de origem, ou ainda, realizarem a propaganda antimilitarista no território. A oposição deveria ser derrotada em todos os espaços, inclusive internamente, fosse quem fosse.

A Itália, a partir de 1922, sofreu a influência fascista e teve Benito Mussolini como principal líder ${ }^{3}$. Esta ideologia de extrema direita, nacionalista e que defendeu a centralização de tudo no Estado, era contrário as ideias liberais defendidas pelos EUA. Os

\footnotetext{
${ }^{1}$ Red Scare pode ser traduzida como ameaça ou alerta vermelha, pois foi uma política contra as ideologias de esquerda, principalmente contra o anarquismo e o socialismo. A sociedade acreditou que o "perigo" vinha de fora, ou seja, com os imigrantes. Neste sentido, o aparato repressivo voltou-se contra certos grupos estrangeiros, dentre eles, os italianos. Os resultados da Red Scare foram prisões e deportações, além, é óbvio, da censura e do controle em relação aos "vermelhos" e imigrantes.

2 ZIMMER, Kenyon. "The whole world our country": immigration and anarchism in the United States, 1885-194. Doctor of Philosophy. University of Pittsburgh, 2010.

${ }^{3}$ GIRON, Loraine Slomp. As sombras do Littorio. O fascismo no Rio Grande do Sul. Porto Alegre: Parlenda, 1994.
} 
anarquistas desenvolveram muitas campanhas contra o avanço do fascismo. E, este último, convocava todos os italianos, do território ou no exterior, a participarem do seu movimento. Essa política italiana fazia com que o governo estadunidense desconfiasse dos imigrantes dessa origem.

Conforme Franzosi', a "Marcha sobre Roma", de 1922, marcou o início das relações ditatoriais na Itália. Perdurando 20 anos de ditadura, o fascismo marcou a política interna e externa da Itália, assim como as relações internacionais do período. Cannistraro ${ }^{5}$ pontuou que Mussolini iniciou os processos de repressão contra os anarquistas e, isso incluiu os defensores de Sacco e Vanzetti. Então, Mussolini prendeu vários anarquistas e acabou inibindo as ações de muitos grupos libertários. E mais, o fascismo defendeu a ideia de que Sacco e Vanzetti não foram condenados por serem italianos, mas por serem anarquistas e "terroristas".

Aqui, através do fascismo como categoria analítica, pode-se verificar a política interna e externa da Itália, a relação dos fascistas com os anarquistas e opositores, e, recordando que as discussões em torno do fascismo abrangem mais que os limites temporais e temáticos deste artigo, podendo ser estendido à Segunda Guerra Mundial, por exemplo.

Neste sentido, procurou-se aproximar alguns conceitos estudados pela história com o caso Sacco e Vanzetti. A preocupação foi a de buscar possibilidades de ensino nesta perspectiva, pensando nos recursos e nas fontes de pesquisa para efetivar a realização. Desta forma, esta série de temas podem ser debatidas através do caso Sacco e Vanzetti. Em outras palavras, um estudo de caso pode levantar várias alternativas de discussões em sala de aula. Portanto, apontam-se algumas possibilidades de ensino de história a partir do caso Sacco e Vanzetti.

Os objetivos deste artigo são: 1) conhecer a trajetória de Sacco e Vanzetti e o seu contexto; 2) estudar os conceitos que podem ser explorados a partir do estudo de caso, aproximando os estudantes do fazer historiográfico, já que eles problematizariam e verificariam o teor dos conceitos em seus respectivos espaços temporais e geográficos; 3) pensar a utilização dos recursos e das fontes a serem trabalhados na investigação histórica.

\footnotetext{
${ }^{4}$ FRANZOSI, Roberto. The Rise of Italian Fascism (1919-1922): Changing Social Relations in Revolutionary Periods. Emory University and Italian Academy of Columbia University, 2013.

${ }^{5}$ CANNISTRARO, Philip V. Mussolini, Sacco-Vanzetti, and the anarchists: the transatlantic context. Chicago: The Journal of Modern History, mar. 1996, p. 31-62.
} 
Das hemerotecas às cartas dos dois sujeitos. Do livro didático as consultas nos sítios virtuais que publicam artigos.

\section{AS TRAJETÓRIAS DE SACCO E VANZETTTI}

Para apresentar Nicola Sacco e Bartolomeo Vanzetti, prefere-se uma breve descrição das suas vidas, sem grandes problematizações, pois, conforme o objetivo central do artigo, a ideia foi inspirar os professores quanto as possibilidades de ensino a partir das diversas fontes que o professor pode utilizar na sala de aula.

A narrativa utilizada foi a base para o levantamento dos conceitos a serem questionados posteriormente. Deste modo, tornou-se perceptível que Sacco e Vanzetti consideravam-se agentes históricos, conscientes de suas posições sociais, e possuíam a convicção de que o contexto mundial interferia na condenação que receberam.

Teoricamente, inspirou-se em Edward Palmer Thompson ${ }^{6}$ e o seu conceito de experiência para conhecer os dois italianos. A categoria experiência pode ser dividida, para fins didáticos, entre experiência vivida e experiência percebida ${ }^{7}$. Desta forma, o conjunto de ações e fatores que a pessoa (con)vive pode não ser percebido, ou seja, é apenas vivido pelo sujeito. Entretanto, a pessoa pode perceber-se como um agente de sua história, colaborador de seu grupo e promotor das transformações necessárias para a melhoria pontual e/ou gradativa de sua vida, a isso denomina-se experiência percebida. $\mathrm{Na}$ lógica anarquista desenvolvida por Sacco e por Vanzetti, eles se construíram como agentes fomentadores de uma transformação radical da sociedade, ou, em outras palavras, eram pessoas que transformavam as suas experiências vividas em percebidas, buscando conscientizar os demais quanto a isso.

Dando sequência ao artigo, Nicola Sacco nasceu em Torre Maggiore, na província de Foggia, em 1891. Na propriedade do pai trabalhou até os 17 anos, momento que a situação

\footnotetext{
${ }^{6}$ Maiores informações, consultar: THOMPSON, E. P. A Miséria da Teoria ou um planetário de erros: uma crítica ao pensamento de Althusser. Tradução: Waltensir Dutra. Rio de Janeiro: Zahar Editores, 1978. THOMPSON, E. P. Costumes em Comum: Estudos sobre a cultura popular tradicional. Tradução: Rosaura Eichemberg. São Paulo: Companhia das Letras, 1998.

${ }^{7}$ ALVES, Giovanni. ARAÚJO, Renan. Thompson, Lukács e o conceito de experiência: um diálogo mais que necessário. Revista Mundos do Trabalho, 2013| p. 53-70.
} 
financeira mudou e a crise no setor agrário não perdoou aquela família. Então, dos dias tranquilos aos dias da emigração, Sacco $^{8}$, escreveu:

[...] a precariedade na qual se bate a existência de todo pequeno proprietário da Itália, a curiosidade natural de todo adolescente, o desejo de afrontar o desconhecido, de experimentar sensações novas, de criar para si, por sua atividade, por sua clarividência, um mundo no qual cada um possa reivindicar seu direito natural a existência, me impulsionaram a emigrar.

Ele emigrou em 1908, quando ocorreu um "ano terrível de desocupação, de miséria, de fome". Esta situação da conjuntura lhe fez confessar: "experimentei já minhas primeiras desilusões". Das primeiras decepções até se transformar em um dos "bons soldados da revolução" ${ }^{10}$, existiram momentos determinantes na vida de Sacco, tais como a constituição da sua família, tendo Rosina como esposa e um casal de filhos.

Bartolomeo Vanzetti era natural de Villafalletto, província de Cuneo, Piemonte. Nascido em 1888, conviveu com os seus vizinhos camponeses até os 13 anos, pelo menos. O seu pai defendeu a necessidade dos estudos, o que, pelo que pareceu, marcou a identidade deste anarquista até os seus últimos dias.

Imigrou nos EUA em 1908, possuindo experiências migratórias, pois, em 1901, foi trabalhar como comerciante na cidade de Cuneo. Outra experiência ocorreu em Turim, quando obteve uma grande decepção pessoal com o trabalho, o que o forçou a retornar para a cidade natal. Lá permaneceu até a morte da mãe, quando decidiu: era hora de partir!

O sonho de fazer a América o motivou e, ao deixar a sua cidade, destacou: "assim deixei a terra que me viu nascer; um vagabundo sem pátria" ${ }^{11}$. Os meios de transporte utilizados foram, respectivamente, o trem, nos dois primeiros dias e, mais sete, em um vapor pelo mar até a "terra prometida". No período havia grandes movimentos populacionais da Europa para a América. Neste contexto, a imigração italiana nos EUA se destacou. Então, conforme Grossutti ${ }^{12}$ :

\footnotetext{
${ }^{8}$ SACCO, Nicola. Zinn, Howard. Felicani, A. (Orgs.). Sacco y Vanzetti: sus vidas, sus alegatos, sus cartas. 1a ed. - Cuidad de Buenos Aires : Terramar, 2011, p. 42

9 SACCO, 2011, p. 42.

${ }^{10}$ SACCO, 2011, p. 131.

${ }^{11}$ VANZETTI, Bartolomeo. Zinn, Howard. Felicani, A. (Orgs.). Sacco y Vanzetti: sus vidas, sus alegatos, sus cartas. 1a ed. - Cuidad de Buenos Aires : Terramar, 2011, p . 30.

${ }^{12}$ GROSSUTTI, Javier. Italian Mosaicists and Terrazzo Workers in New York City. Estimating the Size, Characteristic and Structure of a High-Skill Building Trade. Columbia University: The Italian Academy for advanced studies in America. 2007, p. 1. Disponível em: http://italianacademy.columbia.edu/sites/default/files/papers/paper_fa07_Grossutti.pdf
} 
Esta "nova imigração" foi composta predominantemente por eslavos, judeus e italianos. Aumentando de forma constante a partir da década de 1880 (nos últimos 25 anos do século 19, os EUA receberam cerca de 800 mil italianos), o influxo da Itália atingiu proporções explosivas após 1900. Nos primeiros quinze anos do século, mais de três milhões de italianos entraram nos EUA. Constituíram a maior nacionalidade da "nova imigração" e mais de vinte por cento da imigração total desse período ${ }^{13}$.

Desta "nova imigração", a maioria não era de trabalhadores especializados. Sacco e Vanzetti estavam incorporados nesta camada de imigrantes, ou seja, naquela que não possuía especialização. Por isso eles vagaram entre ocupações e lugares, sempre, aprendendo e se mantendo conforme a disponibilidade de vagas de emprego.

Vanzetti procurava por uma vida melhor, com melhores condições de vida. Para isso, virou vendedor ambulante de peixes e enguias, então, em 1920, foi preso acusado de um assalto seguido de morte. Foram 7 anos detido, todos eles envolvidos entre a cadeia e o tribunal. Entre recursos e apelos internacionais, vivia entre a esperança de uma nova possibilidade no processo e no desespero de vê-las exaurirem-se com o passar dos dias.

Vale salientar que eles conheceram o anarquismo em solo estadunidense. Ambos foram militantes ativos nos EUA. Vanzetti participou de manifestações, encontros e greves operárias. A anarquia que ele defendeu pode ter sido o principal motivador para a sua execução, mantendo-se convicto de sua inocência e do porquê de sua condenação.

Sacco declarou que ao chegar nos EUA, ele era "quase ignorante das questões

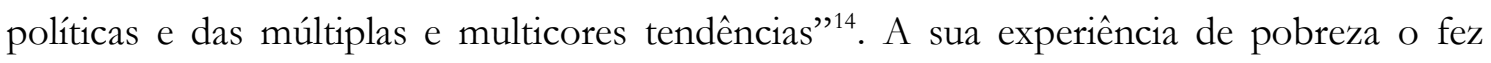
ingressar no movimento anarquista. Um exemplo citado como forma de resistência e manifestação foi a ação pública contra a Primeira Guerra Mundial.

Sacco, nos anos de liberdade, pertenceu a Federação Socialista Italiana, estudou em uma escola para imigrantes e se qualificou na área calçadista. Organizava um meeting contra a prisão de Roberto Elia e Andrés Salsedo ${ }^{15}$ quando, junto de Vanzetti, foi preso. Transtornado e indignado com a situação, Sacco, então, questionou: "de que era culpado?

\footnotetext{
${ }^{13}$ Tradução livre do original: “This 'new immigration' was composed predominantly of Slavs, Jews, and Italians. Increasing steadily from the 1880s onwards (in the last 25 years of the 19th century the US welcomed about 800,000 Italians) the influx from Italy reached explosive proportions after 1900. In the first fifteen years of the century, over three million Italians entered the US. They constituted the largest nationality of the 'new immigration' and over twenty per cent of the total immigration of this period".

${ }^{14}$ SACCO, 2011, p. 42.

${ }^{15}$ No dia 4 de maio de 1920, Salsedo foi encontrado morto após ter sido detido e torturado no Departamento de Justiça de Nova York. Salsedo e Elia eram editores do jornal Il Doman, um periódico anarquista.
} 
De um infame, de um atroz crime que meu cérebro não podia conceber”. Destarte, sentenciou:

\begin{abstract}
Meu crime, o único crime, de que estou orgulhoso, é o de haver sonhado uma vida melhor, feita de fraternidade, de ajuda mútua; de ser, em uma palavra, anarquista, e por este crime tenho o orgulho de terminar entre as mãos de verdugo. Porém que tenham logo a coragem de dizê-lo, de gritar ao mundo aos governantes e aos assalariados dos Estados Unidos - que havendo adquirido sua independência em nome da liberdade, eles pisoteiam essa liberdade em todos os atos de sua existência ${ }^{16}$.
\end{abstract}

Aqui percebeu-se a acusação de Sacco contra a "terra da liberdade", a qual condenava duas pessoas por serem anarquistas, ou melhor, libertários e não por crimes $\operatorname{comprovados}^{17}$. "depois de uma conturbada história judicial, em um clima de histeria coletiva, acabaram na cadeira elétrica, vítimas da intolerância e da xenofobia dos EUA daqueles anos: assassinados porque eram italianos e anarquistas" ${ }^{\prime 1}$.

Nas cartas e nos depoimentos apareceram inúmeros argumentos utilizados pela defesa. Uma das principais foi a tradição italiana, na qual existiu o costume de comer enguias e peixes no natal ${ }^{19}$. Este costume foi apresentado para justificar a legitimidade dos álibis de Vanzetti, já que ele era vendedor de peixes e teria sido visto pelos seus clientes no período do crime.

\title{
ENSINANDO CONCEITOS A PARTIR DO CASO SACCO E VANZETTI
}

O primeiro conceito a ser discutido é o de e/imigrante. A situação social, a vontade de buscar "aventuras" no estrangeiro e as condições econômicas deram condições a estes italianos na imigração nos EUA. Não é possível imaginar que a grande maioria dos e/imigrantes fossem totalmente desprovidos de dinheiro, pois, em muitos casos, foram eles os investidores dos próprios empreendimentos migratórios.

\footnotetext{
${ }^{16}$ SACCO, 2011, p. 43.

${ }^{17}$ SACCO, 2011, p. 131.

${ }^{18}$ MARINELLI, Michele. Sacco e Vanzetti, vittime innocenti del pregiudizio razzista. Il calendario del popolo, n. 722, 2007, p. 43-48. Tradução livre do original: "Dopo una tormentata storia giudiziaria, in un clima di isteria colletiva, finirono sulla sedia elettrica, vittime dell'intolleranza e della xenofobia degli USA di quegli anni: uccisi perché italiani e anarchici”.

${ }^{19}$ VANZETTI, 2011, p. 68.
} 
"Não foi a miséria, foi o medo da miséria", diria o Dr. Javier Grossutti ${ }^{20}$. Esta afirmativa oportunizou inúmeras reflexões. Deste modo, quais as motivações levaram Nicola Sacco e Bartolomeo Vanzetti emigrar? Quais os atrativos possuíam os EUA, no período? Houve, em algum momento, controle da saída (da Itália) e entrada (nos EUA) destes e/imigrantes? Destas problematizações, inúmeras possibilidades de debates.

Inicialmente, é pontual discriminar os conceitos junto aos alunos, assim, as diferenças das categorias emigrante, imigrante e migrante devem ser supridas. Sendo, o primeiro e o segundo se tratando movimentos populacionais internacionais, ou seja, entre países, salientando a diferença do emigrante para o imigrante. A partir desta premissa, questionase: quais os meios de transporte utilizados no percurso? Quais os atrativos existentes para tal empreendimento? Quais as dificuldades que, porventura, forçaram a saída destes emigrantes?

Pontualmente, uma boa fonte para conhecimento e consulta é o Glossário sobre migração, que possui alguns conceitos centrais, tais como: Emigração: “Abandono ou saída de um Estado com a finalidade de se instalar noutro" 21 . Imigração: "Processo através do qual estrangeiros se deslocam para um país, a fim de aí se estabelecerem"22. Migrante: "este termo aplica-se, às pessoas e membros da família que se deslocam para outro país ou região a fim de melhorar as suas condições materiais, sociais e possibilidades e as das suas famílias" ${ }^{\text {23 }}$.

A mesma fonte possibilita a consulta de vários outros conceitos, tais como: estrangeiro, repatriação, refugiados, entre outros que determinam as condições dos sujeitos que mudaram de lugar em busca de: emprego, estudo e/ou demais possibilidades. Este documento apresenta os conceitos, cabe então ao professor agir como provocador dos novos conhecimentos, relacionando, com os devidos cuidados, o que existe de forma institucionalizada e legalmente no presente, com as experiências do passado. Portanto, é possível discutir o passado a partir dos conceitos utilizados no presente, assim como é plausível "olhar" os avanços obtidos com o passar dos anos em relação ao direito e as garantias individuais dos migrantes.

\footnotetext{
${ }^{20}$ Maiores informações: http://www.forumeditrice.it/percorsi/forum-fvg/monografie/non-fu-la-miseriama-la-paura-della-miseria-la-colonia-della-nuova-fagagna-nel-chaco-argentino-1877-1881

${ }^{21}$ Organização Internacional para as Migrações (OIM). Glossário sobre migração. Genebra, Suiça, Editora: Organização Internacional para as Migrações, 2009, p. 24.

${ }^{22}$ Organização Internacional para as Migrações (OIM). 2009, p. 33.

${ }^{23}$ Organização Internacional para as Migrações (OIM). 2009, p. 43;
} 
Dando continuidade ao artigo, Pezzica ${ }^{24}$ lançou a reflexão sobre o porquê e/imigrar, pontuando que foram os momentos mais difíceis que forçaram as migrações. Desta forma, destaca-se que a maioria dos imigrantes chegados nos EUA, durante a virada do século XIX para o XX, eram pobres e grande parte sabia trabalhar apenas nas áreas rurais.

O preconceito contra os italianos foi reforçado com outros elementos, tais como a etnicidade e o idioma. Assim, os estudos de Fernandes e Morais ${ }^{25}$ consideraram que "o preconceito de grande parte dos norte-americanos, entretanto, acabou por julgar esses imigrantes" ${ }^{26}$, pois além da condição social destas pessoas, a população deste país se orgulhava da herança anglo-saxã.

Outro problema contextual é o da preocupação contra os revolucionários que poderiam germinar as ideias subversivas no território capitalista, neste ponto, a Revolução Russa foi um marco para a esquerda revolucionária e para os aparelhos jurídicos dos países que planejaram se prevenir daquelas ideias. Nos EUA, a Red Scare foi uma criação que objetivou paralisar a ação anarquista e comunista no país. Internacionalmente e nacionalmente, os EUA se mantiveram atentos contra as ameaças estrangeiras.

Jensen $^{27}$ abordou sobre o avanço histórico da preocupação internacional da polícia dos EUA. No caso, havia a preocupação em monitorar as fronteiras, quem entrava e quem saía era controlado. Jensen citou o assassinato, em 1901, do presidente McKinley para justificar a opinião pública dos estadunidenses contra os anarquistas e "terroristas" do período. Lorenzo Pezzica citou: "O destino dos dois anarquistas italianos, bodes expiatórios de uma onda repressiva lançada pelo presidente Woodrow Wilson contra 'o perigo vermelho', não só agitou a consciência dos homens da época, mas como um fantasma, continuou a agitar a América por décadas"28.

\footnotetext{
${ }^{24}$ PEZZICA, Lorenzo. L'indebile mito di Sacco e Vanzetti. Bolletino 10. Incontri. Roma, 1997, p. 56-58. ${ }^{25}$ FERNANDES, Luiz Estevam. MORAIS, Marcus Vinícius. Os EUA no século XIX. In: KARNAL, Leandro [org]. História dos Estados Unidos: das origens ao século XXI. São Paulo: Contexto, 2007, p. 86 -148 .

${ }^{26}$ FERNANDES. MORAIS, 2007, p. 133.

${ }^{27}$ JENSEN, Richard Bach. The United States, International Policing and the War against Anarchist Terrorism, 1900-1914. Terrorism and Political Violence, Vol. 13, No. 1, Frank Cass, London, 2001.

${ }^{28}$ PEZZICA, Op. Cit, p. 56. Tradução livre do original: "Il destino dei due anarchici italiani, capri espiatori di un'ondata repressiva lanciata dal presidente Woodrow Wilson contro 'il pericolo rosso', non solo smosse le coscienze degli uomini dell'epoca, ma come un fantasma continuò ad agitare l'America per decenni".
} 
Flavia Tudini ${ }^{29}$ destacou que a Red Scare foi intensificada quando "o governo federal tentará impedir, com métodos no limite da legalidade, a propagação da ideologia subversiva e radical" 30 . De um lado, o governo reprimindo os trabalhadores, anarquistas e imigrantes, do outro os anarquistas com a ação direta. Deste modo, "la red scare raggiunge l'apice di violenza negli anni 1919-1920, a seguito di diversi attentati dinamitardi anarchici”, sendo, 1920, o ano do assalto e do assassinato que Sacco e Vanzetti foram acusados.

Uma fonte importante e que serve para os estudos sobre o contexto é a imprensa. Mas antes, há a necessidade de criar a crítica em relação ao texto jornalístico, e não o aceitar como verdade absoluta. Vanzetti construiu uma categoria interessante para imprensa, quando falou que os jornais eram órgãos que publicavam interesses e leituras de mundo de determinados grupos. Deste modo, deve-se questionar quem são os editores, os chefes ou donos do jornal. Pode-se criar um histórico através das publicações e das posições referentes a assuntos a serem determinados pelo professor. Pensar a linguagem e os seus valores é fundamental para a formação de um aluno crítico. Neste sentido,

Toda linguagem é ideológica porque, ao refletir a realidade, ela necessariamente a refrata. Há sempre, queira-se ou não, uma transfiguração, uma obliquidade da linguagem em relação àquilo a que ela se refere. Por usa própria natureza, de mediadora entre nós e o mundo, a linguagem apresenta sempre, inelutavelmente, um descompasso em relação à realidade. Ela não é, nem pode ser a realidade. A essa diferença substantiva entre a linguagem e o real acrescentam-se as diferenças adjetivas, quer dizer, as variações próprias às posições históricas e sociais dos agentes que a produzem e consomem ${ }^{31}$.

Quando os alunos perceberem que a linguagem é ideológica e dotada de interesses particulares ou de classe, eles devem olhar para os textos de maneira crítica. Então, conforme Graça Caldas, para "além de uma mera instrumentação de conteúdos e demonstração do processo de produção da notícia" ${ }^{32}$. Assim o educando percebe a historicidade das posições que os redatores e editores constroem nos seus artigos. Além disso, os alunos conscientizados da ideologia existente nas palavras escrevem e defendem os seus argumentos de maneira mais consciente.

29 TUDINI, Flavia. Sacco e Vanzetti: caso giudiziario o affaire? Diacronie. Studi di Storia Contemporanea. 2013.

${ }^{30}$ Tradução livre do original: "il governo federale cercherà di prevenire, con metodi al limite della legalità, il diffondersi dell'ideologia sovversiva e radicale".

${ }^{31}$ SANTAELLA, L. Produção de linguagem e ideologia. São Paulo: Cortez, 1996, p. 330-331.

${ }^{32}$ CALDAS, Graça. Mídia, Escola e leitura crítica do mundo. In: Educ. Soc., Campinas, vol. 27, n. 94 , 2006, p. 117-130. P. 122. Disponível em http://www.cedes.unicamp.br 


\section{RECURSOS E FONTES}

Toda fonte e todo recurso utilizado em sala de aula deve ser problematizado. É imprescindível pensar nos objetivos, nas utilidades e nos resultados que eles estabelecem tanto na investigação histórica, quanto no processo de ensino e aprendizagem. Compreende-se que não é possível desenvolver grandes pesquisas com os alunos, seja pelo pouco tempo disponível, seja pela maturidade cognitiva. Porém, é viável apresentar as fontes, as problematizações e os métodos utilizados pelos historiadores contemporâneos. Neste sentido, o estudo de caso pode auxiliar na compreensão do trabalho do historiador.

O jornal é uma das principais fontes utilizadas, pois ela apresenta várias notícias de um tempo, de uma sociedade e do modo de pensar dos editores. Ampliando a questão, torna-se identificável algumas tendências ideológicas e os acontecimentos de um determinado recorte temporal. Destarte, as hemerotecas digitais são muito úteis, pois disponibilizam o acesso às fontes graças à conexão com a internet.

Contando ainda que a utilização da internet como mecanismo de pesquisa facilita a compreensão da diversidade existente entre os elementos linguísticos, ou seja, a forma como ocorre a comunicação nas redes sociais, entre pessoas, e aquela utilizada nos jornais. Portanto,

O papel da escola, especificamente do educador, é estender o uso dos meios de comunicação de casa até a escola, assim nela, os alunos podem ter a satisfação de aprender, utilizando-se dos mais variados recursos; e obter, em decorrência disso, um resultado positivo acerca da língua e da linguagem, já que o homem vem, cada vez mais, criando meios para suprir suas necessidades de se comunicar e interagir com o mundo que o cerca. Cada tipo de linguagem tem e apresenta a sua própria natureza, e se manifesta por diferentes tipos de elementos linguísticos e, através deles, os extralinguísticos. A linguagem produzida no ciberespaço é um exemplo desse processo ${ }^{33}$.

A utilização da internet na Escola colabora para o conhecimento. Empregar criticamente os seus recursos integra o ensino e aprendizagem contemporâneo, pois, de qualquer forma, os alunos mantêm contato com a internet e, se os professores não se

\footnotetext{
${ }^{33}$ LAIS, Cláudia. O uso dos gêneros digitais na sala de aula. Anais Eletrônicos. I Simpósio Regional de Educação/Comunicação, 2010, p. 7. Disponível em: http://geces.com.br/simposio/anais/anais2010/
} 
posicionarem, eles sentirão dificuldades de desenvolver a criticidade no seu manuseio. A utilização das tecnologias da informação também aponta que

a escola sofreu mudanças significativas com os avanços tecnológicos que ocorreram após a Revolução Industrial que se difundem muito mais nos dias de hoje com a propagação do uso da Internet. O leitor competente domina habilidades que vão além da capacidade de decodificar os códigos da leitura e da escrita ${ }^{34}$.

Deste modo, trabalhar com a pesquisa na internet é, de toda forma, uma colaboração para o aprendizado pleno e responsável dos educandos. Além do mais, a mudança na grafia e na utilização de certos termos na linguagem jornalística ajudam o aluno perceber as transformações do próprio idioma. Sem esquecer que não basta ensinar os educandos a decodificarem os códigos da leitura e da escrita, é preciso ampliar a crítica em relação ao conteúdo e a forma como são escritos os textos. Quanto ao acesso aos jornais, cabe a utilização da internet enquanto recurso, pois ela permite muitas possibilidades de pesquisa.

Aponta-se duas hemerotecas virtuais que podem ser consultados. A primeira é a do Grupo Folha ${ }^{35}$ e a segunda é a Hemeroteca Digital Brasileira, da Biblioteca Nacional ${ }^{36}$. Nestes sítios é possível pesquisar por data ou palavras-chave ou por periódico. Por possuírem jornais da década de 1920, é possível investigar a trajetória do caso Sacco e Vanzetti na imprensa brasileira.

Destaca-se a possibilidade de consulta no acervo do jornal The New York Times ${ }^{37}$, o qual disponibiliza a pesquisa em seus jornais antigos, mas dependendo da necessidade, torna-se necessário comprar o artigo. Este periódico de grande circulação publicou inúmeras páginas a respeito do caso Sacco e Vanzetti, tornando-se assim em uma fonte muito rica de informação. O limite da sua utilização se dá pelo seu idioma, ou seja, o inglês. Porém, é possível selecionar alguns trechos e pedir para os alunos traduzirem para o português, seja com o apoio do professor de Língua Inglesa ou não.

A ausência do assunto nos livros didáticos deve ser preenchida com outras referências bibliográficas. Artigos de sítios virtuais e acadêmicos devem ter a leitura acompanhada pelo professor, pois, conforme a linguagem, há a imaturidade intelectual para

\footnotetext{
${ }^{34}$ ANHUSSI, Elaine Cristina. O uso do jornal em sala de aula: sua importância e concepções de professores. Presidente Prudente: [s.n], 2009, p. 41.

${ }^{35}$ Link: http://acervo.folha.uol.com.br/.

${ }^{36}$ Link: http://memoria.bn.br/hdb/uf.aspx .

${ }^{37}$ Link: http://timesmachine.nytimes.com .
} 
compreender os significados de muitos conceitos utilizados pelo(s) autor(es). Estes textos podem ser encontrados em sítios de buscas, tais como o Scielo, nas revistas eletrônicas de artigos acadêmicos e/ou no Google de forma geral.

O professor que acompanha os alunos no "mundo virtual" pode problematizar questões novas a cada instante, já que a internet disponibiliza qualquer assunto a partir de um "click". Assim, o docente deve estar preparado para manter a qualificação profissional, pois os alunos exigem um novo ritmo de ensino e aprendizagem que envolvem esse tipo de “conexão". Deste modo,

Do livro e do quadro de giz à sala de aula informatizada e on-line a escola vem dando saltos qualitativos, sofrendo transformações que levam de roldão um professorado menos perplexo, que se sente muitas vezes despreparado e inseguro frente ao enorme desafio que representa a incorporação das TIC ao cotidiano escolar. Talvez sejamos os mesmos educadores mas os nossos alunos já não são os $\operatorname{mesmos}^{38}$.

A partir da percepção de que os estudantes possuem outros interesses, e cabe ao professor ajuda-los a encontrar as melhores informações, participando das suas trocas sociais na internet, pontua-se na necessidade da atualização quase que diária dos professores no gyber espaço. Neste ponto, apresenta-se a fotografia como recurso digital determinante e instigante. Problematizar este recurso/fonte, significa:

Fotografia é memória e com ela se confunde. Fonte inesgotável de informação e emoção. Memória visual do mundo físico e natural, da vida individual e social. Registro que cristaliza, enquanto dura, a imagem de uma ínfima porção de espaço do mundo exterior. É também a paralisação súbita do incontestável avanço dos ponteiros do relógio: pois o documento que retém a imagem fugidia de um instante da vida que flui ininterruptamente ${ }^{39}$.

A fotografia, deste modo, é recurso e é fonte. Ela por si contém imagens passiveis de leituras e interpretações, porém, ela possui uma intencionalidade orientada pelo fotógrafo. Neste sentido, a necessidade de estudos avançados a respeito do seu conteúdo, levando em que conta que ela não deve ser percebida "como um assessório a linguagem verbal/escrita, mas como sendo mais uma fonte de análise histórica, a qual pode ser muito reveladora e

\footnotetext{
${ }^{38}$ BELLONI, M. L. Educação a Distância. Campinas, SP: Autores Associados, 1999, p. 27.

${ }^{39}$ KOSSOY, B. Fotografia e história. São Paulo: Ática, 1989, p. 101.
} 


\section{histórias}

\section{história}

instigante a que se permite estudá-la profundamente" ${ }^{40}$. Mas, ressalta-se, sem dados externos precisos, pode não ser possível identificar a data, o local e as pessoas (se caso houver) fotografadas.

O sítio virtual de Massachusetts disponibiliza algumas fotos sobre Sacco e Vanzetti. $\mathrm{Na}$ imagem é possível identificar os trajes, as expressões e as algemas. Os rostos deles foram publicados em diversos jornais, com cada periódico orientando os significados do caso à sua maneira.

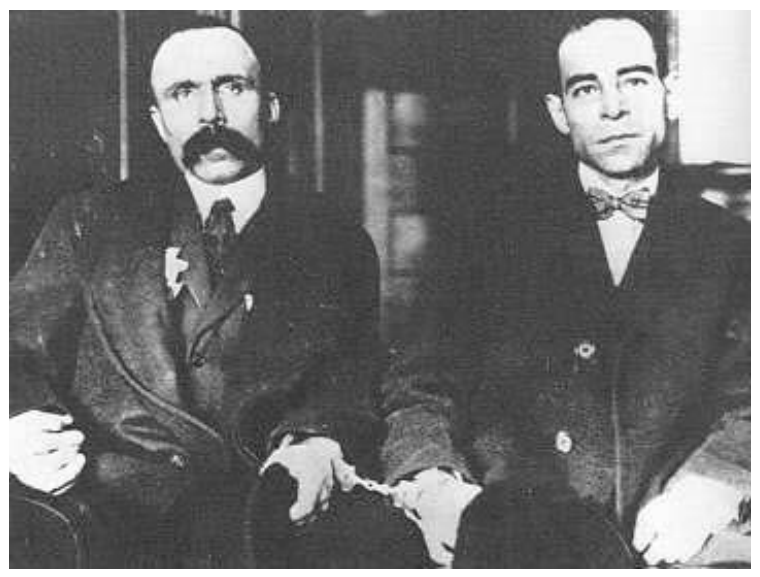

Figura 1 Bartolomeo Vanzetti e Nicola Sacco.

Fonte: bttp:// www.mass.gov/courts/images/sjc/edu-res/saco-van/sacvan.jpg

Nos jornais os seus rostos nem sempre eram publicados através das fotografias. O desenho, a gravura e a caricatura ilustravam aqueles dois condenados. Um exemplo é o jornal $A$ Manhã, o qual anunciava que o governo Fuller não aceitava os pedidos de clemência enviados para ele.

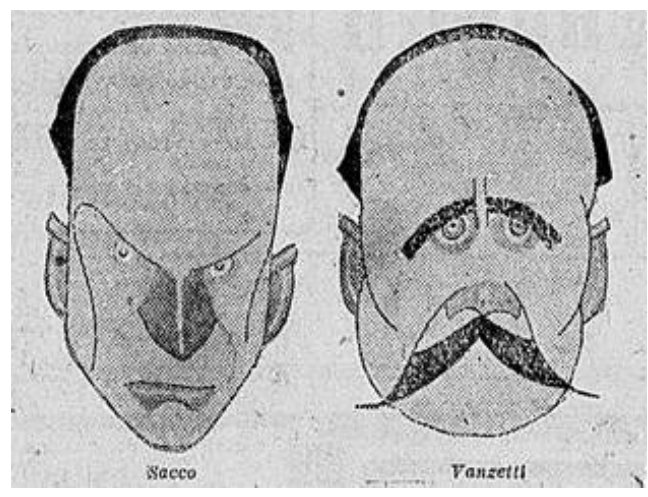

${ }^{40}$ SCHNELL, Rogério. $O$ uso da fotografia em sala de aula Palmeira: espaço urbano, econômico e sociabilidades - a fotografia como fonte para a história - 1905 a 1970. S.D. P. 6 In: http://www.diaadiaeducacao.pr.gov.br/portals/pde/arquivos/5-4.pdf 


\section{histórias}

história

Figura 2 Ilustração no jornal $A$ Manhã, do dia 4 de agosto de 1927, p. 1.

O jornal porto-alegrense Correio do Povo publicou, em agosto de 1927, a notícia referente as manifestações da Federação Operária do Rio Grande do Sul (FORGS), defendendo os anarquistas italianos. Os trabalhadores filiados a FORGS escreveram uma moção de protesto contra a condenação. Coube ao jornal publicar as informações e, de forma ilustrativa, estampar os rostos de Sacco e Vanzetti para que os leitores conhecessem eles.

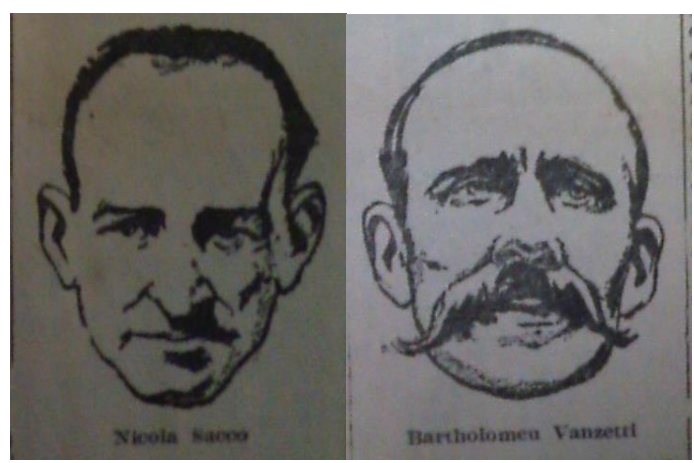

Figura 3 A condenação à morte de Sacco e Vanzetti. Correio do Povo. 10 de agosto de 1927 p. 5

Estes jornais publicavam para o maior público possível. Enquanto isso, existiam periódicos voltados para a classe trabalhadora, ou, ainda, redigido por grupos, entre eles, destacam-se os anarquistas. Em Porto Alegre, O Syndicalista era o órgão oficial da FORGS e, em 1926, ainda possuía anarquistas em seus quadros que estavam preocupados na formação dos militantes sul-rio-grandenses. Neste sentido, o caso Sacco e Vanzetti servia para exemplificar a luta ideológica existente entre os libertários e a burguesia. Então, $O$ Syndicalista defendeu os italianos e condenou o processo que culminou na execução de ambos. Para eles, o principal motivador foi ideológico.
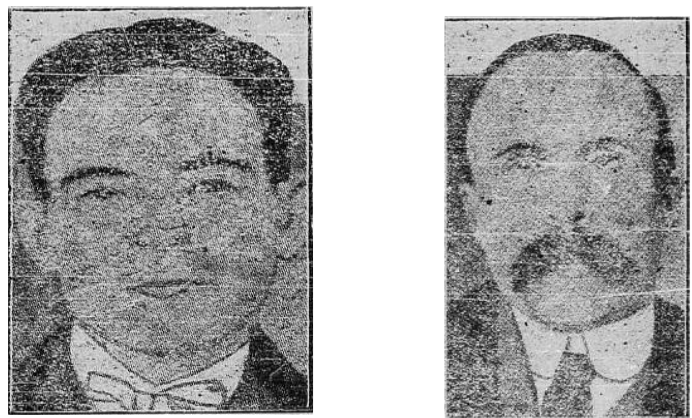

Figura 4 Louvor aos mártires da Liberdade. O Syndicalista, Maio de 1928, p. 2. 


\section{histórias}

história

Após a execução, a função do mártir estava consumada. Os dois italianos, crendo na visão libertária, morreram defendendo o anarquismo. Nicola Sacco declarou, nas suas últimas palavras: “viva a anarquia!". Se a ideologia era o motivador da execução, Sacco não negou a sua, muito pelo contrário, a defendeu até o seu último momento de vida. Vanzetti proclamou: “eu sou inocente!”. Não havia mais defesa e nem acusação, a execução estava consumada. Restava as últimas homenagens aos restos mortais e, no caso dos anarquistas, perpetuar as mensagens deles.

A veracidade de tal afirmativa pode ser percebida no cortejo e nos monumentos póstumos erguidos para não deixar esquecer deste caso. O cortejo foi seguido por milhares de pessoas. Os jornais de vários lugares escreveram, publicaram e se posicionaram frente ao caso. A matéria vendia muito bem. As pessoas consumiam aqueles conteúdos. Os anarquistas se revoltavam.

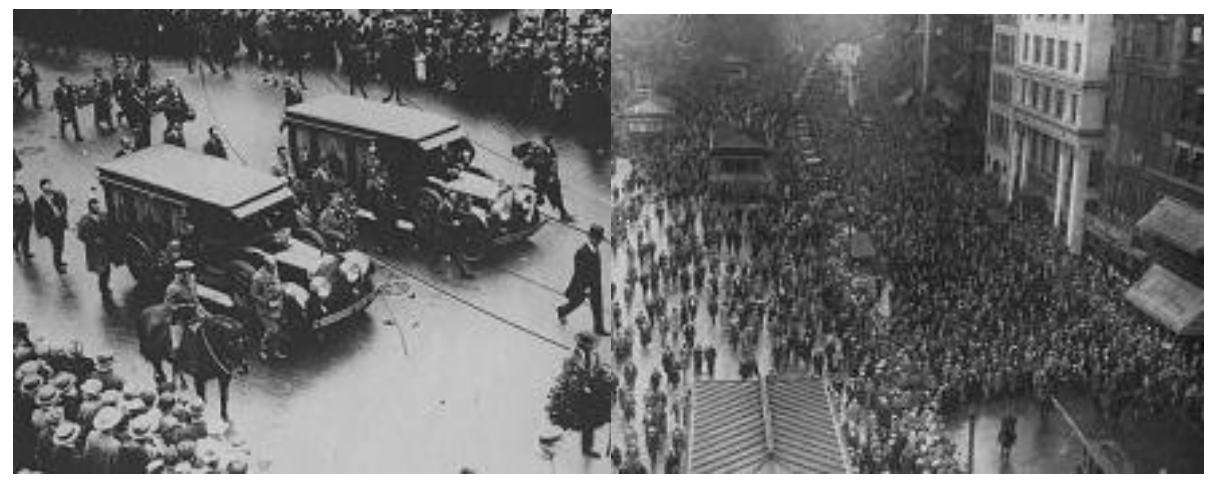

Figura 5 Fotos do cortejo fúnebre de Sacco e V anzetti.

Fonte: http:// wnw.mass.gov/courts/court-info/sjc/edu-res-center/saco-vanz/ the-executions-and-funeral-20-gen.html

Entre bombas e dinamites, ocorrem as manifestações de afeto e desilusão. Morreram, em 23 de agosto de 1927, mas permaneceram na memória da esquerda por muitos anos. Enfim, retornando ao debate da utilização das fotografias, Turazzi ${ }^{41}$, destaca que a leitura, a interpretação, a análise e as imagens fotográficas são partes fundamentais do processo de desenvolvimento da capacidade física e intelectual dos educandos. Especificamente falando da fotografia, pontua-se que ela "tornou-se um dos principais meios de acesso à experiência, a uma ilusão de participação" ${ }^{42}$. Em outras palavras, ao estudar as fotografias, é possível imaginar-se na situação, sendo acessível, visualmente, pelo menos, a análise das vestimentas, paisagens e posições que as pessoas e os objetos se encontravam. Estas

${ }^{41}$ TURAZZI, M. I. História e o ensino da fotografia. Projeto Araribá: informes e documentos. São Paulo: Moderna, 2005.

${ }^{42}$ SONTAG, Susan. Ensaios Fotográficos. Lisboa, Dom Quixote, 1986, p. 20. 
possibilidades colaboram para a compreensão e identificação do conhecimento problematizado pelo professor. Em suma, por vivermos rodeados de imagens, ao observar alguma, é imprescindível que os alunos consigam interpretar os seus sentidos e intenções.

De qualquer forma, é importante manter a ideia de que "ao fazer uso das fontes como ferramenta de aprendizagem não se deve, no entanto, descaracteriza-la como documento histórico. O aluno deve perceber de que forma a história é escrita e qual o valor simbólico destes artefatos para determinadas sociedades"43. Os estudantes devem ter o contato com fontes governamentais, com os periódicos, com as fotografias, etc. Eles devem saber que os recursos, as tecnologias, as formas de escrita e os interesses contidos nas fontes/documentos, são frutos do tempo a qual pertencem.

Obviamente, além de apresentar as fontes, o professor precisa instigar os educandos a levantar problematizações e verificações do seu conteúdo. A crítica interna e externa à fonte estabelece o sentido de significação com os objetos ao seu redor, sejam contemporâneos ou registros históricos. Portanto, "é importante no processo de significação que o aluno fará das fontes históricas que este perceba através de outros textos, da ampliação do sentido destas fontes" ${ }^{\prime 4}$. Com isso, esta possibilidade de ensino orienta os educandos para a análise crítica ao(s) "seu(s) mundo(s)" e com o que eles convivem.

Por fim, este capítulo voltou-se para a problematização dos recursos possíveis de serem utilizados em um estudo de caso. Salienta-se que são exemplificações, não receitas. Que é uma verificação de possibilidade, não um plano de aula orientado passo-a-passo. Assim, como estas ferramentas servem para esta provocação temática, elas podem ser utilizadas para vários outros conteúdos. Cabe a disponibilidade, a possibilidade e a predisposição dos agentes que fazem a educação acontecer.

\section{CONSIDERAÇÕES FINAIS}

As considerações finais deste artigo devem servir como problematizações iniciais para novas possibilidades de ensino e aprendizagem em sala de aula. Acredita-se que trabalhar com conceitos pontuais, com recursos e fontes diversificadas, é um diálogo mais

\footnotetext{
${ }^{43}$ XAVIER, E. S. Ensino e História: o uso das fontes históricas como ferramentas na produção do conhecimento histórico. In: XII Encontro Regional da ANPUH-PR. Regiões: imigrações, identidades, 2010, Irati. XII Encontro Regional da ANPUH-PR. Regiões: imigrações, identidades., 2010, p. 647.

${ }^{44}$ XAVIER, 2010, 649.
} 
que necessário. A importância de um ensino crítico, voltado para análises empíricas, ajuda a fomentar estudantes mais atuantes na sociedade.

Não existe um juízo final referente ao caso investigado, se Sacco e Vanzetti eram culpados. Porém, é possível investigar a história a respeito do contexto, dos motivadores e dos resultados do que se convenciona chamar "caso Sacco e Vanzetti". Se a história é feita de fatos, ela é, também, repleta de processos e questionamentos.

O caso Sacco e Vanzetti possibilita a investigação voltada aos detalhes que justificam as ações, as escolhas e os rumos que muitas pessoas escolheram para as suas vidas. Do olhar macro ao micro, o diálogo entre o conteúdo e o fato se faz pertinente, seja com o conteúdo aproximado desta proposta, seja com qualquer outro.

As fontes e os recursos explorados na sala de aula colaboram para uma educação crítica e responsável. Os jornais, os sítios de busca e a constituição de acervos digitais devem ser melhor explorados na educação, já que os estudantes consomem boa parte deste material, basta os professores focarem nos objetivos específicos e realizarem as críticas internas e externas a estes meios.

A linguagem e a forma como as fontes são disponibilizadas entram no debate, já que nada pode ser considerado neutro, ou, ainda, imparcial, o levantamento de conteúdos que estão fora do livro didático colaboram para o questionamento da sua ausência. 